\title{
Research and Library Skills: An Analysis
and Interpretation
}

Stephen K. Stoan

This study examines the source of misunderstandings between librarians and teaching faculty over the concepts of library use and of research, concluding that library skills and research skills, being predicated on divergent philosophies of information seeking, are essentially different things that can be, and usually are, learned in isolation from each other. It goes on to discuss some possible implications of these findings with regard to bibliographic instruction and to some other library policies.

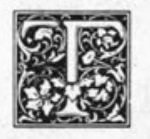

he concepts of library use and of research have generated much misunderstanding between teaching faculty and librarians. One hears librarians accuse faculty of not knowing how to use the library. The faculty often claim that librarians do not understand research. Part of the impetus toward library-use instruction, which shaded off first into "bibliographic" instruction, then into teaching students to do "research" in the library, derives from the conviction that the faculty, not knowing how to use the library, are somehow incompetent in teaching their students how to do research properly. And some faculty complaints about the library derive in no small measure from their perception that, not understanding research, librarians end up organizing the library, its services, and its resources in terms of their own logic, not that of researchers. The purpose of this paper is to explore the reasons for these divergent views in the hope of creating a clearer understanding among librarians of the teaching faculty, who to a considerable degree remain an unknown and unstudied quantity.

For librarians, it seems, the reference search strategy they learned in library school, or some variation thereof, is synonymous with "knowing how to use a library." Although they are vague on how many reference tools one must know to be a good library user, it is certain that, as librarians see it, the more access and synthetic tools in more disciplines one knows, the better one knows how to use a library. Library skills tests, which almost everyone but professional librarians routinely fail, are a tribute to this attitude toward library use.

The insistence of librarians on the efficacy of reference search strategy as the best technique for gathering information leads them in some cases to desire to teach it as an end in itself. Bibliographic instruction units become minicourses in basic reference, sometimes with contrived assignments, reminiscent of those utilized in library school, designed to make students learn how to use this or that reference tool. Librarians also tend to conceive of learning library skills in incremental terms, depending on the level of the student, though some freshman programs, such as that at UCLA, are rather elaborate at the outset, with units on the card catalog, indexes and abstracts, government documents, newspapers, encyclopedias, dic-

Stephen K. Stoan is head of reference, Wichita State University Libraries, Kansas. 
tionaries, book reviews, plot summaries, etc. - in short, the complete menu of types of reference tools. ${ }^{1}$ From the freshman level, librarians move on to course-related bibliographic instruction, in which they present the same types of reference tools geared to specific disciplines. Some of the more recent proposals for teaching search strategy emphasize not only the sources but also the process-that is, the sequence according to which one consults different types of reference tools. But all library information-seeking models, whether source- or process-oriented, rely almost exclusively on reference tools. ${ }^{2}$

If librarians' conception of using a library is more or less synonymous with reference search principles and strategy, what do they mean by research? Though they understand what research means at a scholarly level, in practice they tend to use the word interchangeably with the expression library use. They speak of teaching students, even freshman composition students, "research strategies," or how to do "research in the library." Thus they use the term loosely to refer to a technique for gathering information in the library utilizing tools in the reference collection. And many, like Daniel Gore, tend to assume that there is a single research strategy applicable to all disciplines. ${ }^{3}$ It is only necessary in moving from one field to another to apply the principles learned.

The logic of using these access and synthetic sources seems so evident to librarians that they are alternately critical, bemused, or amused when they observe that faculty members fail to use them consistently. Lubans summarizes these attitudes when he writes: "Users have a distorted (often superior) view of their knowledge of library skills..... Instructing a user in this situation is a delicate and difficult task, particularly when teaching faculty are involved. It is difficult to teach those who assume they don't need to learn what is being taught. ${ }^{\prime 4}$ In a similar vein, Sharon Rogers writes that "by the conventional standards of the literature model based on library sources, user study after user study had demonstrated the teaching faculty's general incompetence to use the library."
An obvious question now arises: if scholars do not know how to use a library, how do they do research successfully? Indeed, what is research as viewed by scholars and how does the library fit into it? Research, as scholars see it, is a scientific process of expanding knowledge in a more or less cumulative way within a discipline. The researcher formulates a hypothesis, constructs a research design, gathers empirical data, and tests the hypothesis against the data gathered, offering some kind of conclusion, however tentative. Each discipline has its own kind of primary data (that is, data uninterpreted by others) and its own techniques for gathering and testing that data, though there are similarities in research techniques in related disciplines. As scholars see it, research can only be conceived within the context of a discipline, whose methodology one must master. The methods of the physicist do not serve the archaeologist or the historian.

The genuine core of a research project, then, consists of essentially uninterpreted data, many or all of which may be gathered outside of the library altogether, as in a laboratory or archive, or from a questionnaire or case study. For the scholar, library use comes into play for the gathering of some primary data in some disciplines and for the gathering of secondary literature, that is, the books, articles, and research reports in which are reported the results of research. This secondary literature of the scholar is what librarians call primary literature. Since scholars must master this primary literature in their disciplines, it follows that library use is one aspect of research.

If, however, research practitioners are not routinely using reference tools to identify the primary literature, how are they doing it? The evidence on this point is substantial. In gathering citations, scholars demonstrate a preference for the footnotes and bibliographies included in the primary literature itself. The INFROSS study at Bath University of Technology on the information-gathering habits of researchers in the social sciences revealed a clear-cut preference for following footnotes and bibliographies in the subject lit- 
erature. Ninety-four percent of respondents in this study found references in books and periodicals to be useful in locating materials for research. ${ }^{6}$ In comparing the actual users of indexes in various disciplines to what they calculated to be potential users, based on subject area, the Bath investigators discovered that the great majority of indexing/abstracting systems were used by fewer than 15 percent of scholars.'

In like manner, Stenstrom and McBride found in their study of the social science faculty at the University of Illinois that only 12.6 percent reported using abstracting journals "usually," compared to 69.4 percent who used footnotes in journals usually and 51.3 percent who used footnotes in books usually. Those who "rarely or never" used abstracting journals were 50 percent, compared to 7.3 percent who rarely or never used footnotes in journals and 9.6 percent who rarely or never used footnotes in books. ${ }^{8}$ In a later study confined to the faculty in the Psychology and Educational Psychology departments, both ranked in the top ten in the United States, Stenstrom and McBride reported that fewer than 20 percent of either group "even occasionally used abstracts or bibliographies to identify sources.",

Wood and Bower and Styyendaele undertook studies based on identifying the source of citations being requested by researchers through interlibrary loan. The Wood-Bower study, at the National Lending Library in Britain, revealed that only 21 percent of requests of social science researchers had come from an index or abstract. In specific disciplines, the percentages were lower: political science, 9 percent; sociology, 10 percent; economics, 15 percent; psychology, 15 percent; and education, 17 percent. ${ }^{10}$ Styvendaele studied not only social scientists but also scientists and engineers at the University of Antwerp in 1975-76. The differences between the two kinds of researchers were not great. Social scientists reported finding 14.5 percent of their citations in abstracts, while scientists and engineers reported 15.5 percent. ${ }^{11}$ Styvendaele reviewed the results of several similar surveys carried out in 1963, 1967,
1968, 1971, and 1973, dealing with either scientific or social scientific literature, and concluded that the use of indexes by researchers was declining. ${ }^{12}$

More recently, Stieg reported on a survey among historians designed to discover how they gathered information for research. Historians reported using bibliographies or footnotes in books and articles as their principle source. Stieg noted some anomalies that cast suspicion on the little use of indexes that was reported. Numerous American historians, for example, claimed to use Historical Abstracts; and the single most widely used index, even by scholars in medieval, classical, and Far Eastern history, was reportedly Readers' Guide. ${ }^{13}$ In yet another study, Hernon, in assessing how political scientists and economists obtained information about government documents, reported that they used primarily "citations in their subject literature."14 In fact, the Hernon, Stieg, Wood, Styvendaele, Stenstrom and McBride, and Bath University studies together indicate that footnotes, personal recommendations from other scholars, serendipitous discovery, browsing, personal bibliographic files, and other such techniques that involve no formal use of access tools account for the great majority of citations obtained by scholars.

How is one to interpret this failure of researchers to use consistently the tools that librarians deem so central to the research process? One can, like Stieg, react by accusing scholars of not knowing how to do research properly. ${ }^{15}$ Or one can declare, with the Bath University researchers, that the information-gathering techniques of scholars seem "inadequate, unsystematic, and amateurish," characterized by reliance on a "very low level form of bibliographic control." ${ }^{\prime 16}$ But these same Bath researchers had second thoughts on how to interpret their data. Later in their report, they write:

The information profession sometimes assumes that researchers want to, and can, work in a systematic way in dealing with bibliographical material and that the bibliographical system is about the only system, or at least the most important system, for the transfer of information. In view of the overwhelming evidence that so- 
cial scientists do not perform in this way, such assumptions (sometimes followed by exhortations) should be avoided. User education may go a long way to alerting researchers to potentially useful bibliographic tools and ways of using them; but it is doubtful if it could do more. ${ }^{17}$

Maurice Line, director of the INFROSS study, seems to have acquired a more sophisticated awareness of the infinite variety and nuances of technique and process involved in carrying out research. He writes that "research projects had a variety of origins. Some researchers could state when and how their ideas for research developed, but in the majority of cases the origin of the research was less definite." He adds that "the origins of projects appear to lie largely in their own curiosity and awareness."

After studying a large number of social scientists, Line arbitrarily identified five broad stages in the research process, but noted that "the chronological order of each stage cannot be predetermined, for they vary with the individual researcher's preference for organizing the work. Research is a process that does not allow for too formal organization." "Serendipity," he adds, "plays an important role in research, and information that a researcher comes across merely by chance may cause him to channel his work along new lines." Line noted that researchers may be working simultaneously in several of the stages he identified and are often "'hazy about the way they go about their work. ${ }^{\prime \prime 19}$

What the Bath University investigators discovered is that the research process is an extremely complex and personal one that cannot easily be defined or fit into a mechanistic search strategy. Since few scholars intellectualize what they do, others have had to make the effort to understand research by studying how scholars work. The more recent of these studies strongly emphasize the element of creativity, even subjectivity, in the research process. One such analysis is that of Abraham Kaplan, who developed the concept of "logic-in-use" to apply to the intellectual processes that scholars go through in executing a research project. ${ }^{20}$ The internal logic of the project as it germinates and develops in their minds dictates the sources sought out at each stage along the way. A new idea generated from one source, an original insight springing from another, may alter the direction of the quest and the kind of material being sought. What is needed next will be dictated by the intellectual evolution of the researcher up to that point. The final product of a research project may even be very different from what the investigator envisioned at the outset. In these circumstances, there can be no pat number of predetermined sources that the researcher will consult.

After the fact, of course, one can attempt to "reconstruct" that logic in the hope of delineating a method that can serve as a guideline to how one goes about doing research. But as Kaplan points out, "reconstructed logic" is merely an idealization which, if taken too literally, may hinder future intellectual progress. Confusing the logic-in-use with a particular reconstructed logic may subtly subvert "the autonomy of science." Kaplan notes that there are numerous logics-in-use and reconstructed logics, depending on the discipline and even on the researcher. There are also such things as imagination, inspiration, intuition, and luck or serendipity involved in scientific research. ${ }^{21}$

Polanyi and Ravetz have also elaborated on our inability to describe the research process, which is essentially creative, in formal or mechanistic terms. ${ }^{22}$ Polanyi emphasizes the role of intuition very strongly, ${ }^{23}$ and Ravetz likens the researcher to an intellectual craftsman whose skills cannot be learned through reading, "but from a teacher by precept and initiation" combined with personal experience. $^{24}$

Scholars, then, follow no mechanical procedure of thinking up a topic, doing background reading on it in a synthetic tool, going through the card catalog for books, consulting indexes for articles, going to the Monthly Catalog for documents, checking newspaper indexes for articles, then reading the items located and writing up their findings. Rather, they have read literally hundreds or thousands of books and articles in their field, subscribe to a number of journals, are acquainted with the names of dozens or even hundreds of 
researchers and what they are investigating, heard papers at conferences, corresponded with some fellow researchers, and have often developed personal bibliographic files of considerable magnitude based on footnotes and bibliographies contained in the primary literature itself. The subject literature, after all, forms a vast bibliographic apparatus indexed by subject, according to the book or article in which footnotes appear, and analyzed in considerable detail, for a footnote may cite information contained in a single paragraph or sentence from an entire article or book. Viewed in this light, a mediumsized academic library may actually have more than a million bibliographies, only a small percentage of which are to be found in the reference collection or the Z's.

A fact that must be considered, then, is that to an extraordinary degree the primary literature indexes itself, and does so with greater comprehensiveness, better analytics, and greater precision than does the secondary literature. Footnotes are, after all, the traditional medium whereby scholars communicate with each other directly. That is their purpose. Access literature, because it introduces another layer of human minds through which information must be filtered, analyzed, classified, and labeled, may never be as useful to researchers, who learn that the context in which an item is cited is usually a better guide to its usefulness than an arbitrarily chosen descriptor or subject heading assigned by a third party. Facts, especially in the social and artistic worlds, cannot be readily established, rigorously defined, or easily labeled with precise terminology whose definitions are universally agreed on. There are nuances, subtleties, overlaps, layers of meaning, and perspectives that no indexing system can adequately capture. Terminology changes and new subject headings are created. Terms overlap in meaning. Descriptors can be poorly assigned. One cannot account for all of the vagaries of judgment of indexers and catalogers. And since scholars cite literature outside their own disciplines a great deal-in the various social sciences, between 50 and 64 percent of the time, according to one study ${ }^{25}$-the discipline- centered index is of even more limited use. Seen in this light, it is not at all illogical for a scholar to want to browse books and periodicals, and even to go through an entire run of a journal volume by volume and issue by issue.

There are yet other aspects of the scholar's reticence to rely on access tools. In following the footnotes and often annotated bibliographies incorporated into the primary literature, researchers are obtaining professional guidance from other experts, who are placing citations within an intellectual framework that reveals their relative value and interrelates the parts to a whole. Raw facts devoid of interpretation are meaningless. Information, until worked into some kind of theory or hypothesis that seeks to make sense of it, is meaningless. It is the action of the human mind that converts information into knowledge, and it is knowledge, not simply information, that scholars are seeking. Access tools, unfortunately, are usually mere listings that offer no qualitative assessment of the citations contained.

With regard to the tertiary literature, it is, as a general rule, likely to be even less useful to scholars than the secondary. For if researchers are well informed about their disciplines, information appearing in the synthetic literature will present few surprises. It is already old. The subject encyclopedias that librarians emphasize so heavily are altogether lacking in many disciplines and are infrequently updated where they do exist. Moreover, the tertiary literature merely duplicates what can be found elsewhere. ${ }^{26}$ When scholars need quick factual information in their disciplines, they are likely to have ready at hand in their offices a large number of specialized monographs and current textbooks, all with subject indexes in them. A recent textbook can be an excellent reference tool for quick summary information and definitions. Moreover, it always includes a lengthy and qualitatively selected bibliography for each subdivision of the discipline that few encyclopedias can match. It functions, in short, as a subject dictionary, a subject encyclopedia, and a basic subject bibliography all rolled into one. 
Researchers, then, generally identify much or even all of what they need without recourse to the library's access and synthetic literature. They then use the card catalog and serials list as locator devices. If one understands that reference tools are not basic to literature searching as carried out by scholars, only sometimes useful adjuncts, it will then be obvious why the faculty routinely fail library skills tests. They have never taken a course in basic reference and, if they did, would find much of it irrelevant to their needs and interests.

The scholarly view of research and how one goes about it has important implications for how professors view the curriculum and the logic of undergraduate and graduate education. Since, for them, true research can be carried out only after one has achieved a substantive mastery of the discipline and learned the research methodology peculiar to it, it follows that research will be learned at the graduate level. In professional schools, this usually means the doctoral level. Undergraduate education will concern itself with imparting to students a basic knowledge of the discipline they choose to major in at the outset of their junior year. Therefore, undergraduate courses might often be expected to involve no more than a textbook, outside readings, class discussions or presentations, material put on reserve, or material put on reading lists. They frequently involve no independent literaturesearching in the library.

At the graduate level, where students are specifically learning to be researchers, coursework will reflect a different orientation. Here students are learning the major schools of thought, theses, and interpretations in their disciplines, mastering the research methodology, learning how to gather and analyze the primary data, and undertaking in seminar-type courses to do research under the direct and close supervision of a scholar-adviser. The concept of research as craftsmanship transmitted from master to apprentice, as expounded by Ravetz, becomes important only at this level, where students are few and personal direction possible. Indeed, an understanding of research dynasties is use- ful in understanding major schools of thought, and more than one scholar has commented on the feudal nature of scholarship.

Is there any evidence to verify that, whether consciously or not, scholars do view the educational process in this light? It would seem so. A number of studies of college and university library use as measured by circulation statistics reveals a pattern that has varied little since the 1930 s. The results of these studies-by Branscomb, Knapp, Barkey, Hardesty, Hostrop, Lane, and others-can be summarized as follows: ${ }^{27}$ One, nearly all student use of the library is course-related. Two, a majority of undergraduate students use the library either sporadically or not at all, at least as measured by checkout statistics. Three, a small percentage of undergraduates, generally about $10-15$ percent, accounts for more than half of all checkouts. Four, undergraduate checkouts of materials generally increase by class rank, being lowest among freshmen and highest among seniors. It is even heavier at the graduate level. Five, use of preassigned materials placed on reserve or on bibliographies handed out in class constitutes a high percentage of what use does occur. Independent information-seeking seems to be required by relatively few courses. Six, a few courses on campus generate much of the library use. Knapp's study at Knox College revealed that, in a single semester, 7 percent of the courses generated more than half of all checkouts, 16 percent accounted for 75 percent of checkouts, and 25 percent generated 87.5 percent of circulations. Seven, small, upper-level, elective courses are likeliest to require independent literature searching. And eight, there seems to be no convincing evidence of a relationship between gradepoint average and use of the library.

Along similar lines, one could note that at Wichita State University during the year 1981-82, faculty and master's-level graduate students together generated 37 percent of academic use, averaging 24 and 15.5 checkouts per person respectively. All upperclassmen generated 34 percent of use, averaging twelve books per FTE student. And all underclassmen ac- 
counted for but 22 percent of checkouts, averaging 5.65 books per FTE student. ${ }^{28}$

More striking scientific support of this argument comes from Rambler's recent study at the Pennsylvania State University. ${ }^{29}$ She undertook to obtain a scientific sample of 162 course syllabi selected to represent all colleges and course levels. Using a specially developed typology of library assignments, Rambler analyzed the syllabi to determine the amount of library use required. By much use she meant a course project that caused students to gather information independently, as for a term paper. By some use she meant assignments involving the use of library materials preselected by the professor. And by no use she meant just that.

The results of the study correlate well with the previously mentioned research on library use as indicated by circulation statistics and offer yet other evidence of how the faculty do indeed view the curriculum and structure their courses at different levels. Only 8 percent of the courses required much library use, and 63 percent, nearly two out of three, required no use. More revealing is that in courses ranked 1 through 399 , roughly freshman through junior levels, only 3 percent required much library use and 73 percent required no use. Of those courses at the 400 level or beyond, courses for advanced undergraduates and graduates, 11.5 percent required much use. But even at this level, 56 percent demanded no library use.

If one takes into account that the category "some use" as defined in the study involved no independent literature searching, the fact remaining is that at the freshman through junior levels only three out of one hundred courses demand the kind of library use that course-related bibliographic instruction is ostensibly aimed at. The percentages, of course, may vary from school to school, and may be higher in baccalaureate institutions that lack graduate programs. But the weight of empirical evidence gathered in a variety of ways at a variety of schools over the last half century reveals an obvious and stable pattern.

One can argue that circulation statistics do not tell the whole story of library use, and this is certainly true. But until it is demonstrated empirically that one class of users is likelier than others to use materials in-house (and the heavier in-house users could well be faculty and graduate students), it is logical to assume that circulation statistics are broadly indicative of relative use by different classes of users. Moreover, all evidence accumulated to date seems to point in the same direction, suggesting a logical pattern consistent with the view that the curriculum is so structured as to cause the library's resources to be used primarily by faculty, graduate students, and a small percentage of the undergraduate student body, primarily upper-level students. Those resources are not serving an essentially undergraduate student body with distinctive interests divorced from the curriculum as organized by the faculty. And even a modest shift in the prevailing pattern, as Rambler suggests, could impose an impossible burden on most libraries, given their present level of resources. ${ }^{30}$

\section{SOME CONCLUDING OBSERVATIONS}

Research scholars, who may make significant contributions to knowledge, seldom possess library skills. Librarians, who possess library skills, seldom do research. Indeed, they work in a field whose research tradition is universally acknowledged to be weak. They complain that library schools do not train them to be researchers. From these facts, it must be deduced that research skills and library skills are neither the same thing nor bear any organic relationship to each other. Research skills center on the quest for knowledge; library skills center on the search for information. Research skills involve a mastery of the substantive content of a discipline and of its major schools of thought, an understanding of its research methodology, specialized skills in gathering and testing its primary data, which usually come from outside the library, and an undefinable ability to think "geologically" or "historically" or "biologically." Library skills, though they could be of supplemental use to researchers in a literature search, can be learned simply as a set 
of mechanical skills, divorced from disciplinary considerations, that enable one to find "some" information on almost any topic. One could teach any man-on-thestreet about Library of Congress subject headings, catalog cards, the nature and structure of indexing/abstracting systems and other bibliographies, the mechanics of reading citations, and so on. That same man-on-the-street could then pass a library skills test with flying colors. But he would not then be qualified to do research in anthropology.

This is not to argue that library skills are of use to no one but reference librarians. Undergraduate and graduate students, who are unable to operate with the broad knowledge and solid bibliographic base of research scholars, can find library skills valuable in initiating their first timid efforts at "research." Because professors do not regard undergraduate library projects as true research, only as intellectual exercises designed to get students to play with ideas, they give little thought to the problem of how beginners are to get started. And those beginners are the abandoned souls who end up at the reference desk. In this situation, an introduction to the access and synthetic literature, with all its inconsistencies, fragmentation, gaps in coverage, and problems in indexing, can be for students a significant educational experience, even a revelation. Even for faculty members who are venturing outside their own fields reference tools can be extraordinarily useful, though in this case, professors are likelier to seek advice or recommendations from a colleague who is a specialist in the area in question.

In seeking to develop bibliographic instruction on campus, librarians might keep in mind the following points based on observations made earlier in this paper. In the first place, instruction in bibliographic resources is useless unless wedded to a course project in which students are simultaneously acquiring subject knowledge and direction from the professor and bibliographic skills from the librarian. Second, librarians should be careful not to equate library skills with research skills, for in so doing they risk giving teaching faculty the impression that, for them, research consists of nothing more than identifying an access tool, determining the best subject headings, and, in this way, finding all there is to find. Third, librarians must keep in mind the very limited purposes of instruction in bibliographic resources, recognizing that in the final analysis the teaching faculty are still playing the crucial role of directing the research, giving qualitative guidance, judging the results, and, indeed, deciding if the course is even to include a library component.

A fourth point to consider is that librarians, in their classroom sessions, should overtly recognize the importance of bibliographical information to be obtained from footnotes in the primary literature. Through books and articles, investigators can obtain citations given in an interpretive context that offers some sense of their place in the literature. Access tools are useful in tracking down leads, but the real work of research generally goes on within the framework of the primary literature itself. Also, librarians should emphasize that browsing, too, can be a valuable way of locating pertinent information. Looking through books in a certain call number range in the stacks is certainly more educational than trying to select from among thirty-seven catalog cards under the same subject heading. Fifth, and this is a point that flows logically from the previous one, librarians should recognize that there are no pat techniques, using reference tools alone, that enable students with little knowledge of a discipline to evaluate the quality of information they find. In other words, process approaches all have weaknesses. Book reviews may say much about how a book was received at the time it was published. They say nothing of the place of that book in the literature today, after ten, fifteen, or twenty years of subsequent research and changing interpretations. Judging the quality of articles by the reputation of the journals in which they appear is a proposition based on patently spurious logic. Reviews of research, written as they are by scholars for other scholars, are frequently too sophisticated for the relative newcomer, and they invariably suggest lines of research that only an experi- 
enced scholar or advanced-level graduate student could hope to undertake. Use of citation indexes can be valuable, but these tools, too, have weaknesses that cannot be described at length because of the limited extent of this article. Suffice it to say that in the social sciences and humanities, certainly, techniques of selecting and citing data from other books and articles preclude any broad generalizations about the relationship of citing to cited works. In the last analysis, one must recognize the value to the student of a single key monograph or article recommended by the instructor in the course or identified in another way, for one such item and the bibliography it contains may be of greater worth than hundreds of titles listed in the card catalog or in indexing systems. The objective of bibliographic instruction should be to get students into the primary literature as quickly as possible, for it is here that subject knowledge and scholarly guidance will be found.

A sixth point worth making is that a majority of faculty on campus may never see fit to give course assignments involving independent literature-searching in the library. And, if they do, they may see no reason to seek the services of a librarian. For every professor who will testify to the value of bibliographic instruction and/or library assignments, there will be others who, because of the discipline they teach, their philosophy of pedagogy, the size of their classes, the level of their courses, heavy involvement with graduate programs, or such practical considerations as the work load they are willing to assume, will not give library assignments. Indeed, the limited extent of courses involving library components could be interpreted to indicate that many professors have doubts about the educational benefit of turning undergraduates loose on an independent literature search in a discipline they still scarcely understand-hence the emphasis in most undergraduate courses on assigned readings selected by the professor. Judged by this criterion, some of the worst taught courses on campus may be those that give library assignments with little forethought or direction. In any case, those professors who do put students to work in the library may see no reason to invite a librarian for assistance. Many of these professors may give enough guidance that their students seldom need reference assistance. In the final analysis, the pedagogical views of librarians cannot alter the tradition of the primacy of the professor in the classroom. Course-related bibliographic instruction, therefore, remains uninstitutionalized, dependent exclusively on personal relationships between librarians and teaching faculty.

The key to developing a good program of bibliographic instruction, then, is effective faculty liaison, which depends in the broadest sense on assuaging the sources of "tension and conflict" between librarians and teaching faculty so well described by Biggs. ${ }^{31}$ For purposes of this paper, it would be useful to add to her analysis a few points deriving from the theme of research and library use being treated here. As noted in the initial paragraph of this paper, there is a widespread perception among the faculty that many librarians do not understand research. It is a view that this author first heard in graduate school, almost as a warning, some twenty years ago, and has continued hearing up to the present moment.

What is the source of this attitude? One can attribute it in part to the previously mentioned tendency of librarians to fail to distinguish clearly between scholarly research and a library search strategy, utilizing reference tools alone, designed simply as a technique to aid a literature search. But the problem is broader. Some librarians give the impression that, in their view, the only technique for transferring scholarly information is the access literature. They sometimes even take offense at, or ridicule, researchers who do not use formal bibliographic tools. Those who fail to comprehend the centrality of the primary literature and its footnotes in the research process do indeed betray an ignorance of modern scientific scholarship and the mechanisms it has devised for transmitting research information.

But the problem is broader still. Not only do scholars not generally find indexing systems to be especially comprehensive or reliable, but they also continue to 
insist on the indispensability of browsing and serendipitous discovery. For them, no subject heading or descriptor can adequately analyze a book or article, or suggest ways in which specific sections of those works might be useful for this or that research project. Research, they will insist, is a very personal and creative process. For scholars, therefore, to whom books and journals are the tools of their trade, the full potential of those tools can be realized only through personal manipulation and examination. Any library policy that denies scholars direct, browsing contact with the primary literature on the assumption that indexing systems alone give adequate access is likely to be interpreted as stemming from an incomprehension of the research process.

Among obvious policies that will be so viewed are storage facilities and compact shelving. Another is the tendency among librarians to make decisions with regard to the acquisition or retention of journals based at least partially on indexing considerations. Whether a journal is indexed or not is immaterial to scholars, who judge it according to the quality of the articles it contains. A related and less obvious library policy that can arouse resentment is the classification of journals, which substantially eliminates browsing on the assumption that no one would look at a journal without first consulting an index. Still another area of concern for faculty is large, unbrowsable microform collections, espe- cially of primary literature whose footnotes (endnotes) they may desire to check. Reeling back and forth from text to endnotes on a microfilm reader is a maddening exercise. And in a less tangible but nonetheless important sense, some librarians weaken the image of the profession by giving the impression of looking on books and journals as just so much merchandise, so many units of information, to be purchased, accessioned, cataloged, shelved, identified through access tools, circulated, reshelved, and finally discarded according to some undefinable criterion. These librarians read a great deal about the primary literature; they hardly ever read the primary literature.

The preceeding observations are not meant to suggest that every library can, in every case, accommodate the ideals of research scholars. Practical and inescapable limitations of space and finances must often play the dominant role in decision making. But the terms in which libraries propose or defend their policies can go far in convincing faculty that librarians are sensitive to their needs even when practical exigencies prevent them from satisfying those needs fully. The tone of a policy can be critical in maintaining a spirit of good will. And good will may not only facilitate programs like bibliographic instruction but also engender stronger faculty support for the library and its budgets.

\section{REFERENCES AND NOTES}

1. Miriam S. Dudley, Library Instruction Workbook: A Self-Directed Course in the Use of UCLA's College Library (Los Angeles: College Library, University of California, 1978).

2. See Sharon Rogers' excellent analysis in 'Research Strategies: Bibliographic Instruction for Undergraduates," Library Trends 29:69-74 (Summer 1980).

3. Daniel Gore, "Teaching Bibliography to College Freshmen," Educational Forum 34:111-17 (Nov. 1969).

4. John Lubans, Jr., 'Library-Use Instruction Needs from the Library Users'/Nonusers' Point of View: A Survey Report," in John Lubans, Jr., ed., Educating the Library User (New York: Bowker, 1974), p.401.

5. Rogers, "Research Strategies," p.77.

6. Information Requirements of Researchers in the Social Sciences (2v.; Bath, England: Bath University of Technology, 1971), v.1:62.

7. Ibid., p.84.

8. Patricia Strenstrom and Ruth B. McBride, "Serial Use of Social Science Faculty: A Survey," College \& Research Libraries 40:429 (Sept. 1979). 
9. Ruth B. McBride and Patricia Strenstrom, "Psychology Journal Use," Behavioral and Social Sciences Librarian 2:2-3 (Fall 1982).

10. D. N. Wood and C. A. Bower, "The Use of Social Science Periodical Literature," Journal of Documentation 25:115-17 (June 1969).

11. J. H. Van Styvendaele, "University Scientists as Seekers of Information: Sources of Reference to Periodical Literature," Journal of Librarianship 9:271-72 (Oct. 1977).

12. Ibid., p.274-76.

13. Margaret F. Stieg, "The Information Needs of Historians," College \& Research Libraries 42:554 (Nov. 1981).

14. Peter Hernon, "Use of Microformatted Government Publications," Microform Review 11:241-42 (Fall 1982).

15. Stieg, p.558.

16. Information Requirements, v.1:77

17. Ibid., p.91.

18. Maurice B. Line, Investigation into Information Requirements of the Social Sciences, Research Report No. 5 (Bath, England: Bath University of Technology, 1971), p.3.

19. Ibid., p.18-19.

20. Abraham Kaplan, The Conduct of Inquiry: Methodology for Behavioral Science (San Francisco: Chandler, 1964), p.3-11.

21. Ibid., p.11-15.

22. Michael Polanyi, Personal Knowledge: Towards a Post-Critical Philosophy (Chicago: Univ. of Chicago Pr., 1958); Michael Polanyi, The Study of Man (Chicago: Univ. of Chicago Pr., 1959); Jerome R. Ravetz, Scientific Knowledge and its Social Problems (New York: Oxford Univ. Pr., 1971); a good collection of essays analyzing the influential ideas of Polanyi is to be found in Thomas A. Langford and William H. Poteat, eds., Intellect and Hope (Durham: Duke Univ. Pr., 1966).

23. Polanyi, Study of Man, p.22.

24. Ravetz, p.140-41.

25. Penelope Earle and Brian Vickery, "Social Science Literature Use in the UK as Indicated by Citations," Journal of Documentation 25:129 (June 1969).

26. Librarians are by no means unaware of the weaknesses of access and synthetic literature. McInnis writes: "While some general overall scheme does indeed determine what kind of reference works are produced in a particular field, not occasionally chaotic, unpremeditated policies and whimsy are responsible. Reference librarians often find that sources providing substantive or bibliographic information are fragmented and give uneven coverage of a given field. In the process of assisting a researcher, they frequently discover obvious gaps in the array of reference works in an area of inquiry; thus, the effort to gain access to the information required becomes both irksome and timeconsuming." Raymond G. McInnis, New Perspectives for Reference Service in Academic Libraries (Westport: Greenwood, 1978), p.122.

27. Harvie Branscomb, Teaching With Books: A Study of College Libraries (Hamden, Conn.: Shoe String, 1974), p.17-38; Patricia Knapp, College Teaching and the College Library (Chicago: American Library Assn., 1959), p.13-52; Patrick Barkey, "Patterns of Student Use of a College Library," College E Research Libraries 26:115-16 (March 1965); Larry Hardesty, "The Academic Library: Unused and Unneeded?" Library Scene 4:14-16 (Dec. 1975); Richard W. Hostrop, "The Relationship of Academic Success and Selected Other Factors to Student Use of Library Materials at College of the Desert," (Ph.D. diss., UCLA, 1966), p.53, 148; Gorham Lane, "Assessing the Undergraduates' Use of the University Library," College \& Research Libraries 27:278-80 (July 1966); Nurieh Musavi, "Users and Non-Users of College Libraries" (Ph.D. diss., Univ. of Pittsburgh, 1977); John Lubans, Jr., "Nonuse of an Academic Library," College \& Research Libraries 32:362-67 (Sept. 1971); for a lengthy survey of the literature on this topic, see Lloyd Gene Elliott, "A Study of the Use by Undergraduates of One University Library" (Ph.D. diss., Florida State Univ., 1977), p.9-33. For another resume of these same points, see also Jo Bell Whitlatch, "Library Use Patterns Among Full- and Part-time Faculty and Students," College \& Research Libraries 44:141-42 (Mar. 1983).

28. These data were obtained from the automated circulation statistics of the Ablah Library.

29. Linda K. Rambler, "Syllabus Study: Key to a Responsive Academic Library," Journal of Academic Librarianship 8:155-59 (July 1982).

30. Ibid., p.159.

31. Mary Biggs, "Sources of Tension and Conflict Between Librarians and Faculty," Journal of Higher Education 52:182-201 (Mar./Apr. 1982). 